\title{
SUICÍDIO: O DIFÍCIL DILEMA ENTRE VIVER E MORRER
}

DOI: $10.22289 / 2446-922 X . V 2 S 1 A 13$

\author{
Susana Paulina de Lima Silva ${ }^{1}$ \\ Cássia Angélica Nogueira Barbosa²
}

\section{INTRODUÇÃO}

A morte sob qualquer forma, mesmo sendo a única certeza do fim da existência humana, é um assunto ainda pouco discutido, como uma maneira de evitar a dor, a tristeza e até mesmo a má sorte, na verdade, a morte é vista como um tabu perante a sociedade, não sobra espaço para a vivência desse evento traumático, dificultando para o homem inclui-la em sua rede de pensamento e simbolizá-la. O suicídio é o tipo de morte que rompe de uma forma violenta o vínculo do desenvolvimento humano, fugindo da construção natural do morrer imposta pela sociedade, intensificando assim, a dificuldade da aceitação e elaboração do luto dos sobreviventes ${ }^{(1)}$. O objetivo do suicida, não é propriamente a morte, ela é apenas o caminho mais rápido utilizado para alcançar tal propósito, ele está em busca de uma saída para o conflito em que está vivendo e a morte é o meio usado de forma mais eficaz para alcançar o seu desejo, então o suicida é um homicida que extermina um objeto interno torturante que o ameaça e o perturba ${ }^{(2)}$. Uma vez que o sujeito está enredado na tendência ao autoextermínio, não há escolha pessoal em jogo, existe uma consequência coletiva, pois o suicídio é sim um problema sociológico, que nos mostra algo a respeito da condição sempre negativa de uma sociedade ${ }^{(3)}$.

\section{MÉTODOS}

Esta pesquisa foi realizada por meio de uma revisão de literatura, sendo que as busca do material deu-se na base de dados: SCIELO, BIREME, LILACS e PEPSIC, e dissertações obtidas nos repositórios dos sites das universidades. Os materiais utilizados são publicados em língua portuguesa e escolhidos preferencialmente entre o período de 2005 a 2015. Para um melhor entendimento sobre o tema em questão, foi realizado um levantamento bibliográfico para a revisão de literatura a fim de se encontrar mais familiaridade com o

\footnotetext{
${ }^{1}$ Graduanda em Psicologia pela Faculdade Patos de Minas (FPM).

${ }^{2}$ Psicóloga pós-graduada na área clinica com a abordagem cognitivo-comportamental. Professora da Faculdade Patos de Minas (FPM). E-mail de contato: cassia-psico@hotmail.com
} 

assunto abordado e também para compreender as ideias já enunciadas sobre outros autores sobre o tema em questão e, assim, fluir o desenvolvimento da pesquisa.

\section{RESULTADOS E DISCUSSÃO:}

Com a realização deste trabalho, foram verificadas as seguintes afirmações: não existe uma causa única para o suicídio, este ocorre devido a vários fatores que vão se acumulando na vida do sujeito, desses os quais podem ser desde ambientais, culturais, biológicos, psicológicos entre outros e os meios aos quais podem ser utilizados para prevenir o autoextermínio é através da identificação de sinais, que podem ser externos ou internos, verbalizados ou não verbalizados, o psicólogo deve estar atento para agir logo, o que não se trata de evitar uma doença, antes que ela apareça, mas sim evitar um processo já em andamento. Existimos em uma sociedade em que a angústia e a solidão precisam ser maquiadas, a coerência que nos rege é a produção-consumo, os quais têm que produzir cada vez mais para termos situação de consumir tudo que nos chega aos olhos ${ }^{(4)}$. Enquanto as classes brigam nessa complexa tarefa de definir causa, pessoas continuam sofrendo com os sintomas da doença, com o desprezo da saúde pública e principalmente com a ausência de informação da sociedade e até mesmo da própria família(5).

\section{CONSIDERAÇÕES}

Diante desta pesquisa teórica apresentada, ficou evidente a importância do assunto no contexto atual. Como se pode constatar, é um tema presente para os estudantes de psicologia. Pode se concluir frente esta pesquisa que o suicídio se dá por traumas gerados durante o percurso da vida do sujeito, sendo ela muitas vezes destruidora, pois envolve muitos fatores biopsicossociais.

\section{REFERÊNCIAS}

1. Guarnieri MCM. Morte no corpo, vida no espírito: o processo de luto na prática espírita da psicografia. [Dissertação] [Periódico na Internet]. São Paulo: Pontifícia Universidade Católica de São Paulo; 2001. [acesso em 31 maio 2016].

2. Manhães MP. O enigma do suicídio. Rio de Janeiro: Imago; 1990.

3. Hillman J. Suicídio e alma. Petrópolis: Vozes; 2009. 

4. Albuquerque MP. Loucura e Contemporaneidade da história da loucura aos dispositivos de saúde mental: qual o lugar do louco. Rev. ACTA. 2009;1(1):165-172.

5. Antoniassi Junior G. Nascentes JLB, Souza JP. A esquizofrenia e suas possibilidades de tratamento: uma interface entre reabilitação e a clínica: Rev. ACTA. 2010;2(2):13-19. 